\title{
Study of the Influence of Process Parameters on Surface Roughness When Inconel 718 Is Dry Turned Using CBN Cutting Tool by Artificial Neural Network Approach
}

\author{
M. V. R. D. Prasad, Yelamanchili Sravya, and Karri Sai Tejaswi
}

\begin{abstract}
Inconel 718, a nickel based super alloy is an extensively used alloy in the aerospace industry, marine industry, steam turbine power plants. It is difficult to cut material due to its properties like low thermal conductivity, work hardening etc and retains its strength at high temperatures. Due to low mach inability of this material the worked surface and subsurface are easily effected during machining operations. Therefore surface finish plays a vital role in machining Inconel 718. The objective of this paper is to obtain optimal turning process parameters like cutting speed, feed, and depth of cut resulting in an optimal value of surface roughness for machining Inconel 718 with Cubic Boron Nitride (CBN10) tool insert using Taguchi's design of experiments approach. The experiments are carried out using L9 orthogonal array. Artificial Neural Networks is used to validate the experimental results.
\end{abstract}

Index Terms-Surface roughness, dry turning, Inconel 718, CBN cutting tool, artificial neural network.

\section{INTRODUCTION}

High surface qualities, less tool wear, economy in machining and high performance of the product with reduced environmental impact are the challenges faced by the modern machining industries. The ability to control the process for better quality of the product is significant. Dry turning is the most common machining process used in the industry and as a substitute to wet turning, thereby eliminating the adverse effects such as breathing problems, risk of skin cancer to the operator caused by the cooling fluids. It also significantly reduces the manufacturing costs.

Surface roughness is a significant factor to determine cracks, creep, cavities, Build-up-edges which nucleate on surface of the component thereby influencing its performance. It is important for the components subjected to high thermal and mechanical loads during their use.

Inconel 718, Nickel based super alloy exhibits unique properties such as high temperature strength, high shear strength, high corrosion resistant and good surface ability. It is used in critical applications such as gas turbines, marine applications, pressure vessels, space vehicles, aircraft engines etc. Considering all the above facts, an experiment is carried out to determine the influence of process parameters such as cutting speed, feed and depth of cut on

Manuscript received January 28, 2014; revised April 1, 2014.

M. V. R. D. Prasad is with the Department of Mechanical Engineering, VNR Vignana Jyothi Institute of Engineering and Technology, Bachupally, Hyderabad (e-mail: dpmandava.vnr@gmail.com ) surface roughness of Inconel 718 when dry turned using CBN cutting tool. Analysis is done using a statistical tool and the results are validated using Artificial Neural Networks.

\section{LITERATURE SURVEY}

Ozel et al. [1] utilised regression techniques and neural networks for predicting surface roughness and tool wear in hard turning. They found that neural network has a better prediction capability than regression models.

Ahmari [2] developed empirical models for tool life, surface roughness and cutting force for turning operations. The author used response methodology and neural networks for predicting surface roughness by taking feed, speed, depth of cut and nose radius as inputs.

J Paulo Davim et al. [3] used the ANN to validate the results obtained by ANOVA. A multilayer perceptron model was constructed with back propagation algorithm using the input parameters of cutting speed, feed, depth of cut; and surface roughness as output parameter.

Habibollah Haron et al. [4] discussed the concept, application, abilities and limitations of ANN in the machining process modelling. The future trend of ANN is also discussed.

Ersan Aslan et al. [6] optimized cutting parameters when AISI 4140 steel is hard turned using Al2O3+TiCN mixed ceramic tool and used Analysis of Variance to analyse the experimental results.

Many researchers carried out their work using PVD and ceramic cutting tools and analysed the experimental results using some statistical tools. Cubic Boron Nitride (CBN) cutting tool is not much used and also validation of results is not done in most of the papers. Therefore, this paper presents the study of the influence of input process parameters on surface roughness when Inconel 718 is dry turned using Cubic Boron Nitride cutting tool and validation of results are done using Artificial Neural Networks.

\section{EXPERIMENTATION}

The workpiece material used is Inconel 718 alloy with chemical composition mentioned in the Table I. The hardness of material is tested using Rockwell hardness tester under the load of $100 \mathrm{~kg}$ and the indent used is $1 / 16$ th inch ball diameter. It is found to be HRB 80 .

Inconel 718 cylindrical bar of $450 \mathrm{~mm}$ length and $25 \mathrm{~mm}$ diameter is cut in to nine $50 \mathrm{~mm}$ long segments. Dry turning is done on all the nine work pieces using CNC Lathe TL20 
shown in the Fig. 1. The machined work pieces are shown in the Fig. 2. The tool holder PCLNL $2525 \mathrm{M}-12$ and the cutting tool Cubic Boron Nitride (CBN 10) used for machining.

TABLE I: CHEMICAL COMPOSITION OF INCONEL 718

\begin{tabular}{|c|c|}
\hline Element & Weight (\%) \\
\hline $\mathrm{C}$ & 0.05 \\
\hline $\mathrm{Mn}$ & 0.18 \\
\hline $\mathrm{Si}$ & 0.13 \\
\hline $\mathrm{Cr}$ & 18.2 \\
\hline $\mathrm{Ni}$ & 52.7 \\
\hline $\mathrm{CO}$ & 0.23 \\
\hline $\mathrm{Al}$ & 0.31 \\
\hline $\mathrm{Mb}$ & 2.99 \\
\hline $\mathrm{Cu}$ & 0.11 \\
\hline $\mathrm{Ti}$ & 0.86 \\
\hline $\mathrm{Nb}$ & 5.03 \\
\hline
\end{tabular}

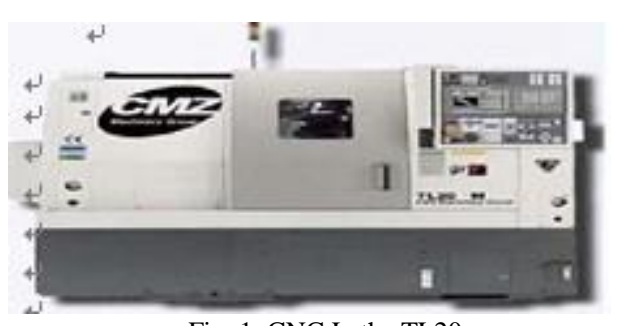

Fig. 1. CNC Lathe TL20.

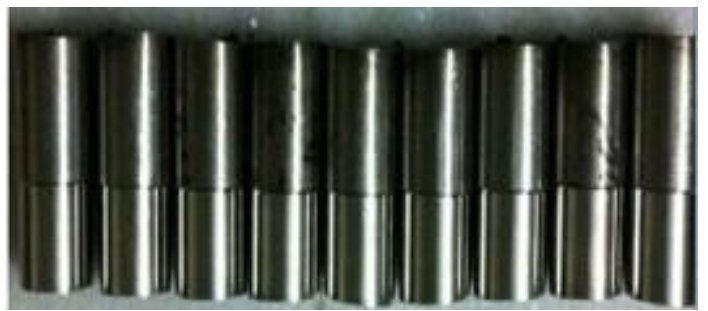

Fig. 2. Machined work pieces.

A $3 \times 3$ array as shown in the Table II is considered as recommended by cutting tool manufacturer.

TABLE II: LEVELS AND FACTORS

\begin{tabular}{|c|c|c|c|}
\hline Factors & $\begin{array}{c}\text { Cutting } \\
\text { Speed(m/min) }\end{array}$ & Feed (mm/rev) & $\begin{array}{c}\text { Depth of Cut } \\
(\mathrm{mm})\end{array}$ \\
\hline Level 1 & 50 & 0.103 & 0.50 \\
\hline Level 2 & 60 & 0.137 & 0.75 \\
\hline Level 3 & 70 & 0.164 & 1.00 \\
\hline
\end{tabular}

Based on Taguchi design L9 orthogonal array plan of experiments as shown in Table III.

TABLE III: L9 ORTHOGONAL ARRAY

\begin{tabular}{|c|c|c|c|}
\hline Trails & $\begin{array}{l}\text { Cutting speed } \\
(\mathrm{m} / \mathrm{min})\end{array}$ & $\begin{array}{l}\text { Feed } \\
(\mathrm{mm} / \mathrm{rev})\end{array}$ & $\begin{array}{l}\text { Depth of cut } \\
(\mathrm{mm})\end{array}$ \\
\hline 1 & 50 & 0.103 & 0.50 \\
\hline 2 & 50 & 0.137 & 0.75 \\
\hline 3 & 50 & 0.164 & 1.00 \\
\hline 4 & 60 & 0.103 & 0.75 \\
\hline 5 & 60 & 0.137 & 1.00 \\
\hline 6 & 60 & 0.164 & 0.50 \\
\hline 7 & 70 & 0.103 & 1.00 \\
\hline 8 & 70 & 0.137 & 0.50 \\
\hline 9 & 70 & 0.164 & 0.75 \\
\hline
\end{tabular}

Using the above set of values the nine pieces are machined and surface roughness $(\mathrm{Ra})$ values are noted in Table IV using digital surface roughness tester.

TABLE IV: EXPERIMENTAL RESULTS OF SURFACE ROUGHNESS VALUES RA

\begin{tabular}{|c|c|c|c|c|}
\hline Trails & $\begin{array}{c}\text { Cutting speed } \\
(\mathrm{m} / \mathrm{min})\end{array}$ & $\begin{array}{c}\text { Feed } \\
(\mathrm{mm} / \mathrm{rev})\end{array}$ & $\begin{array}{c}\text { Depth of cut } \\
(\mathrm{mm})\end{array}$ & $\begin{array}{c}\text { Surface } \\
\text { roughness }(\mu \mathrm{m})\end{array}$ \\
\hline 1 & 50 & 0.103 & 0.50 & 0.44 \\
\hline 2 & 50 & 0.137 & 0.75 & 0.82 \\
\hline 3 & 50 & 0.164 & 1.00 & 0.95 \\
\hline 4 & 60 & 0.103 & 0.75 & 0.38 \\
\hline 5 & 60 & 0.137 & 1.00 & 0.39 \\
\hline 6 & 60 & 0.164 & 0.50 & 1.32 \\
\hline 7 & 70 & 0.103 & 1.00 & 0.29 \\
\hline 8 & 70 & 0.137 & 0.50 & 0.34 \\
\hline 9 & 70 & 0.164 & 0.75 & 1.04 \\
\hline
\end{tabular}

\section{EXPERIMENTAL ANALYSIS}

The plan of the experiment is developed for assessing the influence of the cutting speed, feed rate, and depth of cut on surface roughness $\mathrm{Ra}$.

\section{A. Main Effect Plots of Surface Roughness Ra}

It is observed from the Fig. 3 that as the cutting speed increases from $50 \mathrm{~m} / \mathrm{min}$ to $60 \mathrm{~m} / \mathrm{min}$, the surface roughness reduces. Further increase in the cutting speed to $70 \mathrm{~m} / \mathrm{min}$ decreases the surface roughness. The above trend of decreasing the surface roughness with an increase in cutting speed is because of the thermal softening effect that prevails in machining of Inconel 718. As the Inconel 718 has low thermal diffusivity, the rate of heat transferred to the surrounding from the machining region is very less. As a result, more heat gets accumulated in the machining zone. This leads to thermal softening of machined surface, which facilitates restructuring of the machined surface thereby wiping of the flaws and defects and therefore surface roughness reduces as the cutting speed increases. It is observed from the analysis of means in Fig. 3 that as the feed rate increase from $0.103 \mathrm{~mm} / \mathrm{rev}$ to $0.137 \mathrm{~mm} / \mathrm{rev}$, the surface roughness increases gradually. Further increase in the feed rate to $0.164 \mathrm{~mm} / \mathrm{rev}$ causes drastic increase in the surface roughness. At higher feed rate, the friction between work material and cutting tool will be higher due to larger cross sectional area in deformation zone and therefore surface roughness increases. And also, it is observed from the main effect plot in the Fig. 3 that as the depth of cut increases from $0.50 \mathrm{~mm}$ to $0.75 \mathrm{~mm}$, the surface roughness increases. However, further increase in the depth of cut to $1.00 \mathrm{~mm}$ causes reduction in surface roughness. This can be attributed to the fact that with an increase in the depth of cut, more amount of material in deforming volume leads to severe plastic deformation and therefore the machined surfaces show high surface roughness. However, further increase in depth of cut causes increase in temperature on account of increase in frictional heat due to more contact between tool and work material. Thus higher machining temperature leads to thermal softening of work material resulting in less surface roughness.

Therefore, from Fig. 3 and Table IV it is found that the 
machining at $70 \mathrm{~m} / \mathrm{min}$ cutting speed with $0.103 \mathrm{~mm} / \mathrm{rev}$ and $1.00 \mathrm{~mm}$ depth of cut produced lower surface roughness.

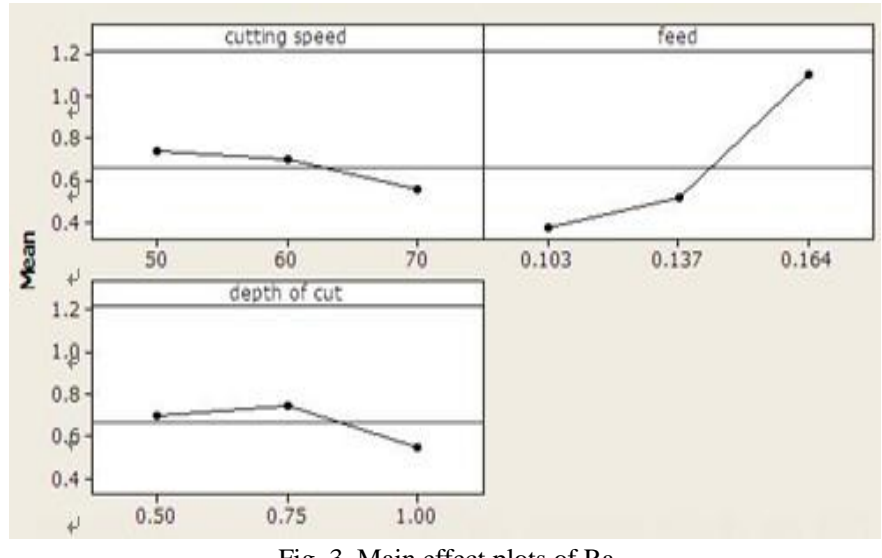

Fig. 3. Main effect plots of Ra.

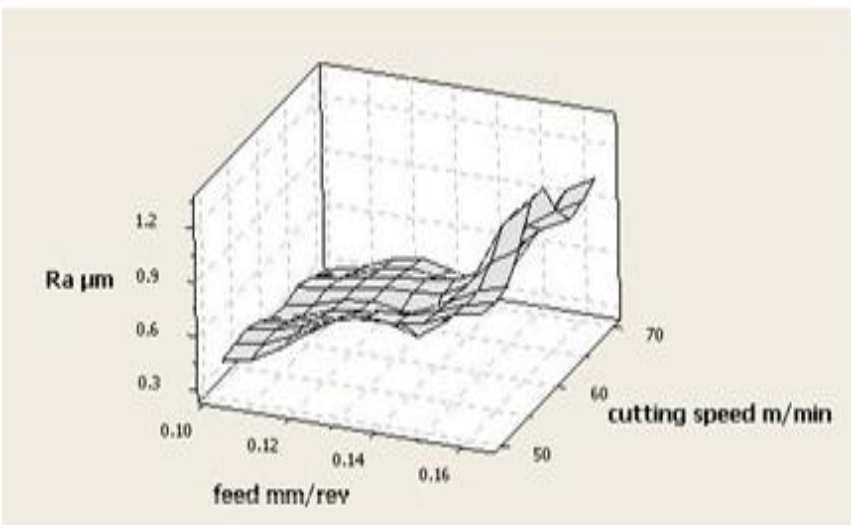

Fig. 4a. Surface plots for surface roughness Ra vs Cutting speed and feed.

\section{B. Surface Plots of Surface Roughness (Ra)}

From the Fig $4 \mathrm{a}$, it is observed that minimum surface roughness is produced when the feed rate is in the range of $0.10 \mathrm{~mm} / \mathrm{rev}$ to $0.12 \mathrm{~mm} / \mathrm{rev}$ and cutting speed is in the range of $50 \mathrm{~m} / \mathrm{min}$ to $60 \mathrm{~m} / \mathrm{min}$. But when the feed rate increases from $0.14 \mathrm{~mm} / \mathrm{rev}$ to $0.16 \mathrm{~mm} / \mathrm{rev}$ and when the cutting speed changes from $60 \mathrm{~m} / \mathrm{min}$ to $70 \mathrm{~m} / \mathrm{min}$, the surface roughness increases. From the Fig. $4 \mathrm{~b}$, it is observed that minimum surface roughness is produced when depth of cut is $1.00 \mathrm{~mm}$ and feed is in the range of $0.10 \mathrm{~mm} / \mathrm{rev}$ to $0.12 \mathrm{~mm} / \mathrm{rev}$. But when feed rate increases from $0.14 \mathrm{~mm} / \mathrm{rev}$ to $0.16 \mathrm{~mm} / \mathrm{rev}$, the surface roughness increases.

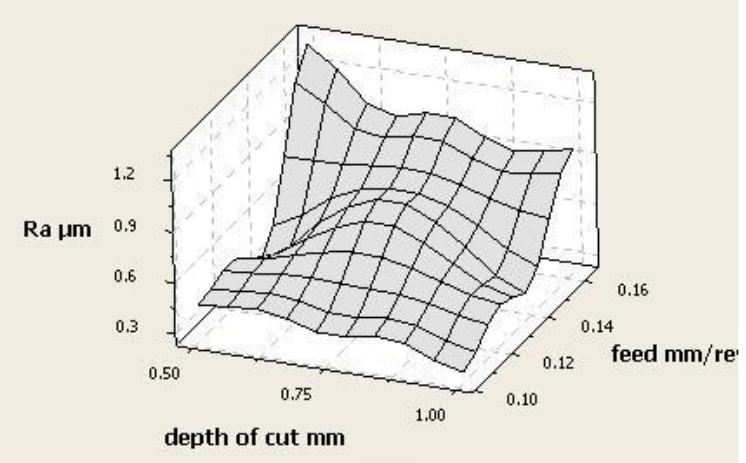

Fig .4b. Surface plots for surface roughness Ra vs feed and depth of cut.

From the Fig. 4c, it is observed that the surface roughness is increased when the depth of cut is in the range of 0.50 $\mathrm{mm}$ to $0.75 \mathrm{~mm}$ and cutting speed is in the range of 50 $\mathrm{m} / \mathrm{min}$ to $60 \mathrm{~m} / \mathrm{min}$. But it is found to be decreased when depth of cut changes from $0.75 \mathrm{~mm}$ to $1.00 \mathrm{~mm}$ and cutting speed from $60 \mathrm{~m} / \mathrm{min}$ to $70 \mathrm{~m} / \mathrm{min}$.

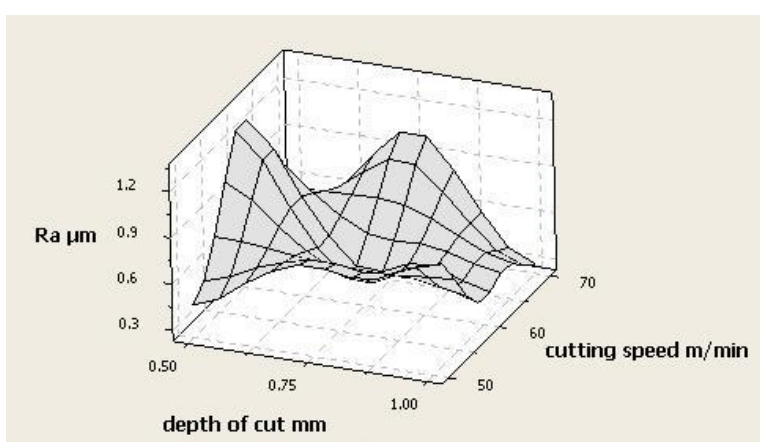

Fig. 4c. Surface plots for surface roughness Ra vs cutting speed and depth of cut.

\section{Validation of Experimental Results Using Artificial Neural Networks}

In the recent years, the application of artificial intelligence is tremendous, virtually in all fields of engineering. Modelling and optimization are necessary for the understanding and controlling any process. Precise control is a prerequisite to achieve improved quality, and productivity. Artificial neural network plays an important role in predicting the linear and non-linear problems in different fields of engineering [3]. In this case artificial neural network is used to evaluate the surface roughness values obtained from the experimental results.

The input data for three independent variables cutting speed, feed, and depth of cut is fed to the network model targeting the response parameter, surface roughness. The network propagates the input pattern from layer to layer until the output is generated. Then the result output is be compared with the target which is actual surface roughness in this study. The error is calculated and propagated back through network. Then, the weight is changed and the same process is repeated until the smallest error is achieved. Hidden layers may be used for more effective analysis. Different models in neural networks are trained using the experimental data. The best neural network model which gives comparatively minute error is taken in to consideration. The model developed for this experiment is Principal Component Analysis (PCA). The predicted values are obtained and error is calculated for each data set as shown in the Table VI. The average percentage error calculated is $2.78 \%$ showing that prediction accuracy is about $97.22 \%$. Fig. 5 shows the plot of predicted surface roughness using neural network and actual surface roughness. It shows that the value predicted.

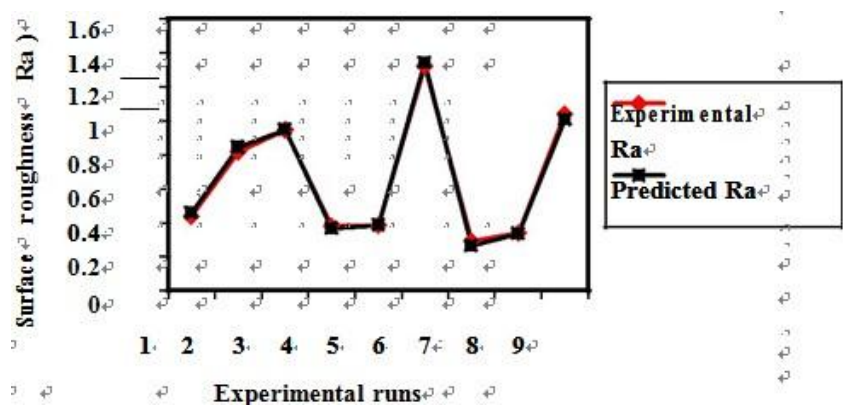

Fig. 5. Plot of predicted using neural networks and actual experimental surface roughness. 
TABLE VI: COMPARISON BETWEEN EXPERIMENTAL AND PREDICTED SURFACE ROUGHNESS VALUES

\begin{tabular}{|c|c|c|c|c|c|c|c|}
\hline \multirow{2}{*}{ Trails } & \multirow{2}{*}{ Cutting speed (m/min) } & \multirow[t]{2}{*}{ Feed $(\mathrm{mm} / \mathrm{rev})$} & \multirow[t]{2}{*}{ Depth of cut (mm) } & \multicolumn{4}{|c|}{ Surface roughness $(\mathrm{Ra})(\mu \mathrm{m})$} \\
\hline & & & & Experimental value & Predicted value & Error & Error $(\%)$ \\
\hline 1 & 50 & 0.103 & 0.5 & 0.44 & 0.45979 & -0.01979 & 4.4977 \\
\hline 2 & 50 & 0.137 & 0.75 & 0.82 & 0.84203 & -0.02203 & 2.6865 \\
\hline 3 & 50 & 0.164 & 1 & 0.95 & 0.95012 & -0.00012 & 0.0126 \\
\hline 4 & 60 & 0.103 & 0.75 & 0.38 & 0.36461 & 0.01539 & 4.05 \\
\hline 5 & 60 & 0.137 & 1 & 0.39 & 0.3901 & 0.0001 & 0.0256 \\
\hline 6 & 60 & 0.164 & 0.5 & 1.32 & 1.33943 & -0.01943 & 1.4719 \\
\hline 7 & 70 & 0.103 & 1 & 0.29 & 0.26712 & 0.02288 & 7.8896 \\
\hline 8 & 70 & 0.137 & 0.5 & 0.34 & 0.33567 & 0.00433 & 1.2735 \\
\hline 9 & 70 & 0.164 & 0.75 & 1.04 & 1.00778 & 0.03222 & 3.098 \\
\hline
\end{tabular}

\section{CONCLUSION}

The following conclusions can be drawn based on the results of the experimentation.It is found that the machining at $70 \mathrm{~m} / \mathrm{min}$ cutting speed with $0.103 \mathrm{~mm} / \mathrm{rev}$ and $1.00 \mathrm{~mm}$ depth of cut produced lower surface roughness in dry machining.

An increase in the cutting speed reduces the surface roughness due to thermal softening effect. An increase in feed rate increases the surface roughness due to the friction between work material and cutting tool. The surface roughness is more sensitive to feed rate followed by cutting speed and depth of cut.

The predicted values obtained from ANN are in close proximity to those of experimental values. The result of the prediction is favourable with $2.78 \%$ average percentage of error, that means neural network is capable to predict the surface roughness up to $97.22 \%$ accurate. It is also observed that ANN is a better model in view of its speed, simplicity and capacity to learn from examples. It does not require more experimental study. It also exhibits good generalization. However, in order to completely describe a process large data points are necessary for ANN training.

\section{REFERENCES}

[1] T. Ozel and E. Zeren, "Finite element modelling of stresses induced by high speed machining with rounded edge cutting tools," ASME
Manufacturing Engineering Division, vol. 16, no. 2, pp. 1279-1287, 2005.

[2] A. M. A. Ahmari, "Predictive machinability models for a selected hard material in turning operations," Journal of Material Processing Technology, vol. 190, pp. 305-311, 2007.

[3] J. P. Davim and N. Muthukrishnan, "Optimization of machining parameters of $\mathrm{Al} / \mathrm{SiC}-\mathrm{MMC}$ with ANOVA and ANN analysis," Journal of Materials Processing Technology, vol. 209, pp. 225-232, 2009.

[4] H. Haron, S. Sharin, and A. M. Zain, "Prediction of surface roughness in the end milling machining using ANN," Expert System with Applications, vol. 37, pp. 1755-1768, 2010

[5] E. Aslan, N. Camuscu, and B. Birgoren, "Design optimization of cutting parameters when turning hardened AISI 4140 steel (63 HRC) with Al2O3+TiCN mixed ceramic tool," Journal of Material Processing Technology, vol. 28, pp.1618-1622, 2007.

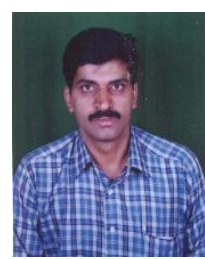

M. V. R. D. Prasd had his engineering education in mechanical/production engineering at K.L.C.E, Vizayawada and P.D.A College of Engineering, Gulabarga. He is presently working as an associate professor of mechanical engineering at VNR Vignana Jyothi Institue of Engineering \& Technology, Hyderabad, India. $\mathrm{He}$ has 18 years teaching experience and a year in the industry. His research interest areas are dry machining, stir welding, and submitted thesis at J.N.T. University, Kakinada for the award of Ph.D. He is having good number of publications in international and national journals and conferences. 